\title{
Consumo, cultura e publicidade: os olimpianos na revista Vogue Brasil
}

\section{Consumo, cultura y publicidad: los olímpicos en la revista Vogue Brasil}

\section{Consumption, culture and advertising: the Olympians in Vogue Brazil magazine}

\author{
Deborah Cunha Teodoro ${ }^{1}$ \\ Universidade Virtual do Estado de São Paulo (Brasil) \\ deborahteodoro@yahoo.com \\ Lucilene dos Santos Gonzales ${ }^{2}$ \\ Universidade Estadual Paulista "Júlio de Mesquita Filho" (Brasil) \\ lucilene.gonzales@unesp.br \\ Mariana Carareto Alves ${ }^{3}$ \\ Universidade Estadual Paulista "Júlio de Mesquita Filho" (Brasil) \\ marianacarareto@gmail.com \\ Renata de Paula dos Santos ${ }^{4}$ \\ Universidade Estadual Paulista "Júlio de Mesquita Filho" (Brasil) \\ renatapstos@hotmail.com
}

Fecha de recepción: 20 de agosto de 2019

Fecha de recepción evaluador: 22 de agosto de 2019

Fecha de recepción corrección: 29 de agosto de 2019

\footnotetext{
${ }^{1}$ Deborah Cunha Teodoro- professora bolsista da Universidade Virtual do Estado de São Paulo, UNIVESP, Brasil. Doutoranda em Comunicação no Programa de Pós-Graduação em Comunicação da Faculdade de Arquitetura, Artes e Comunicação da Unesp de Bauru. https://orcid.org/0000-0002-5955-680X

${ }^{2}$ Lucilene dos Santos Gonzalez - Professora da FAAC, Unesp Universidade Estadual Paulista "Júlio de Mesquita Filho" (Bauru, SP, Brasil). Professora do Programa em Comunicação da Faculdade de Arquitetura, Artes e Comunicação da Unesp de Bauru. https://orcid.org/0000-0003-1659-2533

${ }^{3}$ Mariana Carareto Alves Doutoranda em Comunicação no Programa de Pós-Graduação em Comunicação da Faculdade de Arquitetura, Artes e Comunicação da Unesp de Bauru. https://orcid.org/0000-0002-6657-4010

${ }^{4}$ Renata de Paula dos Santos Doutoranda em Comunicação no Programa de Pós-Graduação em Comunicação da Faculdade de Arquitetura, Artes e Comunicação da Unesp de Bauru. https://orcid.org/0000-0002-5012-6168
} 


\title{
Resumo
}

Sob a ótica antropológica do consumo como um fato social e cultural, o artigo demonstra que as publicidades da revista impressa Vogue Brasil - meses de março e abril de 2019 associam as marcas de luxo a imagens com celebridades - os olimpianos -, projetados como mitos, com os quais as leitoras se identificam com a vida privada desses heróis na cultura de massa. Douglas e Isherwood (2004), Leitão e Pinheiro-Machado (2010), Retondar (2008) e Rocha (2005) sobre o consumo, além do conceito de olimpianos, cunhado pelo francês Edgar Morin (1997) fundamentam a análise das publicidades dessa mídia, cuja fotografia ou ensaio fotográfico dialogam com o imaginário das leitoras e ditam as tendências, lifestyle e consumo de bens.

Palavras-chave: Consumo e cultura; publicidade; moda; revista Vogue Brasil; olimpianos.

\section{Resumen}

Desde el punto de vista antropológico del consumo como un hecho social y cultural, descubriremos que los anuncios de la revista impresa Vogue Brasil, marzo y abril de 2019, asocian marcas de lujo con imágenes de celebridades, los Olímpicos, diseñados como mitos, con qué lectores se identifican con la vida privada de estos héroes en la cultura de masas. Douglas e Isherwood (2004), Leitão y Pinheiro-Machado (2010), Retondar (2008) y Rocha (2005) sobre consumo, además del concepto de olímpicos, acuñado por el francés Edgar Morin (1997) subyacen en el análisis de esta publicidad en los medios, cuya fotografía o ensayo fotográfico, dialoga con el imaginario de los lectores y dicta tendencias, estilo de vida y consumo de bienes.

Palabras clave: consumo y cultura; publicidad; moda Revista Vogue Brasil; Olímpicos

\begin{abstract}
From the anthropological point of view of consumption as a social and cultural fact, we will find that the advertisements of print magazine Vogue Brasil - March and April 2019 - associate luxury brands with images with celebrities - the Olympians -, designed as myths, with which readers identify with the private lives of these heroes in mass culture. Douglas and Isherwood (2004), Leitão and Pinheiro-Machado (2010), Retondar (2008) and Rocha (2005) on consumption, in addition to the concept of Olympians, coined by the French Edgar Morin (1997) underlie the analysis of this media advertising. , whose photography or photographic essay, dialogues with the readers' imaginary and dictates trends, lifestyle and consumption of goods.
\end{abstract}

Keywords: Consumption and culture; publicity; fashion; Vogue Brazil magazine; Olympians. 


\section{Introdução}

Compreende-se, neste artigo, o consumo, sob a ótica antropológica, como um fenômeno cultural construtor de identidades e norteador das relações sociais, com significados culturais. Estruturador de valores que constroem identidades, classificam semelhanças e diferenças na vida contemporânea, o consumo regula relações sociais e define mapas culturais (Rocha, 2005).

Os meios de comunicação, em especial as publicidades, exercem grande influência na sociedade capitalista, traduzindo os afetos, ilusões, desejos e suas características culturais (normas, símbolos, mitos) em imagens, celebridades da TV, internet - os olimpianos (Morin, 1997).

Assim, é objetivo desta pesquisa, associar o conceito de consumo como fato sociocultural e a mediação das publicidades da revista Vogue Brasil entre as marcas de luxo e o público, projetando imaginários com celebridades (olimpianos) e, ao mesmo tempo, efetuando a identificação das leitoras com esses mesmos mitos.

Nos referenciais teóricos, estão as reflexões de Douglas e Isherwood (2004), Leitão e Pinheiro-Machado (2010), Retondar (2008) e Rocha (2005) sobre o consumo, além do de olimpianos, cunhado pelo francês Edgar Morin (1997).

Trata-se de uma pesquisa bibliográfica, descritiva das publicidades da Vogue Brasil, com análise quanti e qualitativa de suas mensagens compostas de fotografias e ensaios fotográficos de celebridades, assinadas por marcas de luxo.

\section{O consumo na sociedade contemporânea: um fenômeno sociocultural}

A compreensão sobre o consumo requer olhar para a configuração da sociedade que sofreu profundas alterações nas suas estruturas desde o advento da revolução industrial e aumento da produção, principalmente a partir do início do século XX, o que consequentemente alterou os hábitos, cultura, percepção do público. Atrelada a isso, os meios de comunicação ganharam um papel de influência na sociedade capitalista, traduzindo os afetos, ilusões em imagens que circulam na subjetividade dos indivíduos, seus desejos, suas necessidades, suas características culturais (normas, símbolos, mitos) e as celebridades - artistas da TV, atletas, homens de negócios, políticos - são "este novo Olimpo, o produto mais original do novo curso da cultura de massa" (Morin, 1997, p. 106).

No que tange ao processo de consumo, esse autor afirma, com base nas ideias de Karl Marx, que o objeto é produzido para o indivíduo, assim como o indivíduo produz o objeto e, como exemplo, destaca a produção cultural em uma sociedade inserida na cultura de massa, a qual cria o público de massa que a consome e, de igual maneira, o imaginário se alimenta do real e vice-versa. Nesse processo, a cultura de massa age para extravasar o imaginário dos indivíduos e conquista a informação para estimular o mundo 
da projeção e da identificação. Isso é realizado por meio da ação da mídia, nos meios de comunicação de massa, que valoriza a vida dos olimpianos, como o autor nomeia as celebridades, para gerar identificação e despertar desejos dos indivíduos espectadores.

Um Olimpo de vedetes domina a cultura de massa, mas se comunica, pela cultura de massa, com a humanidade corrente. Os olimpianos, por meio de sua dupla natureza, divina e humana, efetuam a circulação permanente entre o mundo da projeção e o mundo da identificação. Concentram nessa dupla natureza um complexo virulento de projeçãoidentificação. Eles realizam os fantasmas que os mortais não podem realizar, mas chamam os mortais para realizar o imaginário. A esse título os olimpianos são os condensadores energéticos da cultura de massa. Sua segunda natureza, por meio da qual cada um pode se comunicar com a sua natureza divina, fá-los participar também da vida de cada um. Conjugando a vida quotidiana e a vida olimpiana, os olimpianos se tornam modelos de cultura no sentido etnográfico do termo, isto é, modelos. Encarnam os mitos de autorrealização da vida privada. De fato, os olimpianos, e sobretudo as estrelas, que se beneficiam da eficácia do espetáculo cinematográfico, isto é, do realismo identificador nos múltiplos gestos e atitudes da vida filmada, são os grandes modelos que trazem a cultura da massa e, sem dúvida, tendem a destronar os antigos modelos (pais, educadores, heróis nacionais). (Morin, 1997, p. 107).

A dialética da projeção-identificação intervém nas relações humanas tocadas pela afetividade, abarcando infinitas possibilidades. No imaginário popular, o extraordinário se sobressai ao ordinário, fazendo com que as correntes de projeção dominem as de identificação. No meio dessas projeções ocorre a identificação: o público se sente vivenciando experiências, as quais, na realidade, não são por ele desfrutadas. Para isso, o equilíbrio entre realismo e idealização, condições de verossimilhança e veridicidade são fatores que favorecem a identificação, pois ao mesmo tempo em que o imaginário se constrói acima da vida cotidiana dos indivíduos, as personagens das celebridades demonstram intensidade, amor e riqueza em suas vidas. É nesta troca simbólica que atuam os meios de comunicação, projetando, em seus produtos, uma realidade ilusória que, muitas vezes, supre as carências do público consumidor.

O fenômeno do consumo na sociedade pode ser estudado por diversas perspectivas que explicam sua ação, seus efeitos, reflexos, consequências e aspectos culturais e pode ser interpretado por "sua lógica cultural como via de acesso ao imaginário contemporâneo e, em particular, aquele que se localiza na chamada cultura de massa" (Rocha, 2005, p.125); quatro são os enquadramentos principais para a classificação do consumo na sociedade: o hedonista, o moralista, o naturalista e o utilitarista.

A classificação hedonista é ligada à mais famosa ideologia do consumo e está relacionada ao discurso publicitário, atribuindo o sucesso e a felicidade perene à posse infinita de bens, que seria essencial para a realização pessoal. Para o autor, este enquadramento instaura o mecanismo liberador do contraste para o moralista que, ao contrário, munido de tom denunciatório, acusatório e apocalíptico, admite falar mal do consumo, uma vez que seria responsável por mazelas da sociedade, como problemas sociais que desencadeiam violência urbana, ganância desenfreada e individualismo exacerbado. 
O enquadramento moralista reforça a superioridade moral da produção como algo nobre e valoroso, o sacrifício que engrandece, considerando como mundo verdadeiro o trabalho, a empresa e a profissão, ou seja, a vida levada a sério, em detrimento do consumo superficial, banal e alienador como doença, relacionado ao prazer que condena, à marca, ao gasto e à compra, fúteis e superficiais, como parte de um mundo falso e inconsequente. $\mathrm{O}$ autor estabelece, neste enquadramento, a metáfora com a fábula da obra de La Fontaine "A cigarra e a formiga", em que a cigarra canta, gasta e "consome", enquanto a formiga labora, poupa e "produz".

Já o enquadramento naturalista, como o próprio nome diz, visa a atender as necessidades físicas, como o bem-estar material - se alimentar, vestir e abrigar -, bem como os desejos psicológicos - paz de espírito e recreação -, estando relacionado à natureza, à biologia e ao universalmente experimentado.

Por fim, o utilitarista traz a visão predominante nos estudos de marketing, cuja compreensão do consumo é voltada à produção de resultados de venda.

Essas quatro visões possibilitam uma oportunidade para desconstruir o significado do consumo na sociedade demonstrando que, para além desses significados atribuídos, é possível interpretar o consumo como um "fato social, como fenômeno da ordem da cultura, como construtor de identidades, como bússola das relações sociais e como sistema de classificação de semelhanças e diferenças na vida contemporânea" (Rocha, 2005, p.127).

Fenômeno típico da experiência social da modernidade, o consumo se vale de um sistema de significação suprido pela necessidade simbólica, cuja função essencial é fazer sentido, ao construir um universo inteligível, através de um código que traduz relações, classificando coisas e pessoas, produtos e serviços, indivíduos e grupos, podendo ser inclusivo, portanto, indicativo de identidades e relações sociais. Afinal, "os bens são neutros, seus usos são sociais; podem ser usados como cercas ou pontes", ensinam Mary Douglas e Baron Isherwood (2004, p. 36).

Ao transpor os estudos sobre consumo do ramo da economia para a antropologia, esses autores enfatizam que os bens possuem um perfil social como fornecedores de "serviços de marcação", ou seja, "nos rituais de consumo" criam significados para o momento e para as relações entre os indivíduos, exemplos disso é a teia de serviços oferecidos em um casamento, funeral, aniversário. Nesse caso, “o consumo é um sistema de rituais recíprocos que envolvem gastos para a marcação apropriada da ocasião, seja dos visitantes e anfitriões, seja da comunidade em geral", portanto esses rituais representam marcas normais de amizade (Douglas; Isherwood, 2004, p.40). A partir desse entendimento, os bens são compreendidos como uma necessidade social que faz a mediação das relações entre os indivíduos, e o consumo é visto como um ato de integração social, que cria significados e sentidos para o cotidiano dos indivíduos e suas relações.

Assim, considerando a necessidade social de se relacionar com outras pessoas, a comparação dos padrões de consumo mede o envolvimento social, permitindo aferir o 
gasto com informação, a fim de determinar isolamento ou entrosamento em uma comunidade. Por isso, na antropologia do consumo, o valor de cada coisa depende de seu lugar numa série de objetos complementares e os bens e serviços "são parte da tarefa de realização da vida" (Idem, 2004, p. 45).

Corroborando com esse olhar, Leitão e Pinheiro-Machado (2010) compreendem os objetos e bens como fatos sociais, pois acreditam que é na "interação com eles, no cotidiano, que construímos nossa existência no mundo". Os objetos guardam, produzem, reproduzem e transformam valores, sentidos e comportamento, ajudando a constituir e construir relações, identidades e memórias. Além disso, eles estão em constante contextualização e recontextualização considerando que o consumo e a circulação de produtos podem reconfigurar e modificar seus sentidos e usos.

Ao entender, portanto, a relação entre sujeitos e objetos "podemos conceber as 'cercas e pontes' de Douglas e Isherwood (2004) como sendo construídas, cotidianamente e dentro de contextos específicos, e não apenas expressadas, nas relações de consumo" (Leitão; Pinheiro-Machado, 2010, p. 237). Os objetos fazem parte e estão presentes em todas as relações sociais, por isso eles não devem ser olhados apenas como o consumo no sentido de desejo, posse e troca por dinheiro, mas, principalmente, pelos sentidos que imprimem a essas relações.

Seguindo o raciocínio, essas autoras se embasam nas reflexões de Roland Barthes e Jean Baudrillard para estabelecer uma relação dos estudos do consumo com a moda, demonstrando o uso de objeto para identidade e comunicação dos indivíduos. Para elas, "ainda que Barthes, no Sistema da Moda (2003), trate mais dos discursos sobre as roupas do que propriamente das roupas enquanto discurso, [...] em Mitologias (2001), temos alguns exemplos de como os objetos serão percebidos enquanto um sistema comunicacional; pensamento partilhado e potencializado por Baudrillard, que afirma que os objetos são 'vias de acesso aos sistemas simbólicos da sociedade sendo o consumo a manipulação sistemática de signos"” (Baudrillard 1996, 2002 apud Leitão; PinheiroMachado, 2010, p. 235).

Diante disso, ambos os autores entendem que objetos não possuem significados sozinhos, eles se transformam e criam um discurso quando relacionados entre si e, até mesmo relacionados, a um contexto; ou seja, os sentidos não são construídos "por cada unidade autônoma, mas pelo conjunto e pelo tipo de relação estabelecida entre os termos" (Leitão; Pinheiro-Machado, 2010, p.235). Tal compreensão demonstra que objetos e os indivíduos possuem uma relação comunicacional e, consequentemente, de representação identitária.

Sob esta abordagem, as coisas são concebidas como cultura e o consumo como um sistema de comunicação social, os bens são constantemente associados a distintos universos significativos, sendo tal associação cada vez mais flexível, transformando o consumo num ato de adesão simbólica, em que a escolha do objeto se torna estratégica, com o consumidor definindo e redefinindo, continuamente, sua identidade (Retondar, 2008). Assim, se, num primeiro momento, a sociedade de consumo foi organizada pelo 
viés da padronização, sendo a diferenciação marcada pela proximidade com o estilo de vida e padrão de algum grupo bem estabelecido e legitimado na sociedade; no contexto atual, o elemento marcante parece ser a diferenciação pela identificação.

Assim, a lógica do consumo ultrapassa os próprios objetos, constituindo-se, como uma prática idealista e não material, visto que não se chega a uma saturação, nem a uma satisfação. Dessa forma, compreende-se que "conceitos como necessidade, utilidade e função não passam de noções ideológicas criadas para camuflar a lógica do consumo, que reside na arbitrariedade cultural" (Santos, 2011, p. 128). Por isso, o consumo de produtos e serviços compõe uma lógica abstrata que, segundo a autora, cria um sistema de significado diverso, o qual expressa conceitos de vida e valor "que dão tanto ao consumidor quanto ao bem de consumo uma sólida identidade social no interior de um universo significativo" (Slater, 2002, p. 144, apud Santos, 2011, p. 128).

Se as identidades e subjetividades são construídas e mediatizadas pelo consumo, acredita-se ser possível, como defendem Leitão e Pinheiro-Machado (2010), discutir e refletir sobre a construção de identidades através dos objetos, considerando que eles são repletos de valores para os indivíduos que os consomem, e, portanto, em um contexto específico representam significados para a vida desses indivíduos. Assim, olhar para "para as relações que os sujeitos tecem com eles, procurando perceber como atuam, que valores, sentidos e práticas guardam, produzem e reproduzem" pode ser um caminho para pensar o consumo na sociedade contemporânea (Idem, 2010, p. 244).

Nessa ótica, a relação consumo, organizações e públicos constitui-se um fenômeno cultural construtor de significados para as suas relações sociais mediadas pela comunicação mercadológica a fim de construir um laço de identificação.

\section{Consumo, comunicação marcária e imaginário}

A comunicação mercadológica tem como objetivo criar e/ou manter relacionamento com seus públicos para a construção e consolidação de uma marca, não apenas divulgando um produto ou serviço, mas também disseminando ideias, princípios e valores.

A comunicação mercadológica é a produção simbólica decorrente do plano estratégico de uma organização em sua interação com o mercado, constitui-se em uma mensagem multidirecional elaborada com conteúdos relevantes e compartilhados entre todos os envolvidos nesse processo, tendo como fator gerador as ambiências socioculturais e tecnológicas dos seus públicos de interesse e dos meios que lhe garantam o relacionamento contínuo, utilizando-se das mais variadas formas e tecnologias para atingir os objetivos comunicacionais previstos no plano (Galindo, 2012, p. 109).

E a forma tradicional de as organizações estabelecerem sua comunicação marcária é a publicidade, estratégia fundamental para a construção de imagem e relações de consumo (Galindo, 2008).

A publicidade informa sobre produtos e serviços, construindo significados sobre eles, considerando os contextos dos indivíduos consumidores (Morris; Waldman, 2011). 
Para isso, as campanhas publicitárias se baseiam em práticas e referências culturais e ao mesmo tempo as influenciam, isso porque "ao lado de discursos de vendas, estão textos sociais e culturais que nos ajudam a entender as mensagens do comercial [...] publicidades refletem e moldam simultaneamente a cultura" (Idem, 2011, p. 947, tradução nossa).

Nesse sentido, os discursos que compõem as publicidades representam os significados que a marca quer construir sobre si, o que ela fala e como quer ser vista. Todo o conteúdo expresso nos anúncios, na produção discursiva da publicidade, reafirma a identidade da marca e coloca em circulação sentidos aos seus públicos.

Na criação dessa representação, são unidos elementos como signos verbais, imagens e cenas que contribuem para construção de uma imagem positiva que tenha relação com a identidade desejada. O discurso publicitário aproxima a marca do público consumidor, constrói um imaginário e uma percepção, os quais, no que tange ao consumo, ajudam a gerar a identificação dos indivíduos com a marca, ao disseminar valores que fazem sentidos no contexto sócio-histórico e sociocultural para os indivíduos que os consomem. A publicidade é uma estratégia que colabora para entender o consumo como um fenômeno cultural de representação identitária e mediador das relações sociais. Nela é possível identificar elementos que aproximem os bens das necessidades, expectativas e desejos dos consumidores no contexto em que estão inseridos.

As publicidades de revista, neste artigo, são nosso objeto de estudo para verificar os significados que as marcas disseminam ao público que as consomem, já que as revistas dirigem-se a um perfil de público-consumidor bem definido e em suas mensagens estão representados os afetos, subjetividades desse consumidor.

\section{As publicidades Vogue Brasil: linha editorial e anunciantes}

Optamos pela mídia Vogue Brasil, revista impressa de moda que, mesmo tendo a versão on-line, tem como trunfos no papel a valorização das questões estéticas e a apresentação que convergem com a sua linha editorial, cuja temática e conteúdo são predominantemente imagéticos, indicando tendências, estilos e produtos sempre associados a marcas de luxo. E, sobretudo, essa mídia demonstra uma relação evidente com o consumo de bens e com a identidade dos indivíduos.

No Brasil, a revista mensal é editada pelo grupo Globo em parceria com a empresa Condé Nast, um dos maiores conglomerados internacionais do ramo editorial. Em seu site oficiali, a revista se apresenta como a "bússola das principais tendências de beleza, cultura e lifestyle". Devido ao seu número de leitores e à circulação internacional, a Vogue é considerada a revista de luxo mais influente do mundo tendo como concorrentes as revistas Elle, Estilo e Nova, de acordo com informações de pesquisa disponibilizadas pelo Mídia Kit 2018ii.

E não é apenas no Brasil que a revista Vogue está entre os produtos mais aclamados do mundo da moda. A publicação, idealizada por Arthur Baldwin Turnure e por Harry McVickar, chegou às bancas originalmente em dezembro de 1892, como um 
pequeno folhetim de moda, tendo como público-alvo a alta sociedade nova-iorquina. Hoje, ela está presente em mais de 20 países. A Vogue Brasil possui circulação mensal e foi publicada pela primeira vez em maio de 1975. A tiragem, segundo dados de 2018, é de 78.374 exemplares - 48.244 a partir da circulação paga e 7.401 considerando as assinaturas digitais.

A diretora de redação, Silvia Rogar, classificou a Vogue Brasil como uma publicação influente, criativa e sofisticada que apresenta as tendências ao seu público a partir de uma perspectiva futura, permitindo oferecer informações sobre o que está por vir. Para isso, a revista investe em grandes ensaios fotográficos e se classifica como um veículo de moda conceitual. Todos os meses são publicados sofisticados trabalhos de estilistas, escritores, fotógrafos e designers. As edições valorizam as fotografias e sugerem interpretações ao público quanto ao uso das tendências apresentadas, por isso, não necessariamente, o que o leitor ou leitora encontra nas páginas da Vogue Brasil representa o que é visto na moda cotidiana.

Em relação ao seu público, a publicação tem a mulher como foco potencial: leitora viajada e bem-informada, formadora de opinião no grupo que integra, observada como uma mulher que gosta de possuir coisas de boa qualidade (77\%), se preocupa com a saúde (75\%), valoriza a estética, mantendo a boa forma (72\%) e usando maquiagem para se sentir mais segura. A maioria das leitoras possui dois ou mais carros, faz uso do cartão de crédito, está disposta a pagar mais por produtos de qualidade e tem residência própria. Assim, a mulher Vogue possui um alto poder de consumo e está em busca de uma curadoria para assuntos como moda, beleza e lifestyle. Além disso, a publicação aponta que a sua leitora é, obviamente, apaixonada por moda, tendo um perfil atitudinal. As pesquisas internas apontam que $61 \%$ das leitoras têm entre 35 e 54 anos.

Diante do perfil e números de consumo da revista, a Vogue é considerada uma oportunidade para anunciantes tanto no meio impresso quanto digital. Para isso, a publicação aponta como principais características sua autoridade e influência: autoridade devido à qualidade de seu conteúdo editorial e importância de seus colaboradores; e, influência devido a sua presença em diversos locais do Brasil e grande presença nas mídias sociais.

Com o objetivo de verificar os significados construídos pelas marcas nas publicidades de moda anunciadas na revista Vogue impressa, e considerando sua linha editorial, analisamos as edições de março e abril de 2019.

No total, as duas edições da revista contaram com 86 anúncios de 52 marcas diferentes: Amissima; Animale; Arezzo; Artefacto; Azul Linhas Aéreas; Bela Cozinha GNT; Bottega Veneta; Burberry; Bvlgari Roma; Cartier; Casa Vogue; Celebrity Cruises; Chanel; Cholet; Colcci; Condé Nast; Dior; Dolce \& Gabbana; Emporio Armani; Fendi; Ferri; Glamour; Glamour Brasil \& ESPM; GQ Brasil; Gucci; Havaianas; Hotel Unique; HStern; Ilha Bela Pousada Boutique; Jimmy Cho; Le Lis Blanc; Louis Vitton; Luz da Lua; Michael Kors; Miu miu; Mixed; Mizuno; Monte Carlo; Prada; Prêmio Casa Vogue; 
Rolex; Rosa Chá; Saint Laurrent; Salvatore Ferragamo; Sauer; Silversea; Skecher; Valentino; Verofatt; Vivara; Vogue Brasil \& ESPM; e, Vogue Café.

Chamou-nos atenção que um terço da publicação constitui-se de publicidades: na edição de março, de 222 páginas, 78 são de anúncios; e, na edição de abril, de 204 páginas, 56 são de anúncios, sem contar os publieditoriais constantes na revista.

Oito categorias de produtos e/ou serviços anunciados: alimentação; decoração; educação; eventos; joias e relógios; publicações; turismo; e, vestuário e acessórios. Basicamente, a categoria alimentação foi composta por anúncios de cafeterias; decoração por anúncios de lojas especializadas; educação por anúncios de cursos voltados para moda; eventos por anúncios de divulgação de eventos; joias e relógios por anúncios de marcas; publicações por anúncios de livros e revistas; turismo por anúncios de hotéis, destinos e empresas aéreas; e, vestuários e acessórios por anúncios de marcas de roupas, bolsas, sapatos, óculos e perfume.

Quadro 1 - Frequência de anúncios nas categorias da Revista Vogue

\begin{tabular}{|c|c|c|}
\hline Categorias & Março & Abril \\
\hline Vestuário e acessórios & 33 & 22 \\
\hline Decoração & 1 & 5 \\
\hline Joias e Relógios & 3 & 2 \\
\hline Turismo & 4 & 5 \\
\hline Publicações & 2 & 1 \\
\hline Eventos & 2 & 1 \\
\hline Alimentação & 1 & 38 \\
\hline Educação & 2 & \\
\hline TOTAL & 48 & \\
\hline
\end{tabular}

Fonte: Elaborado pelas autoras.

Trata-se de uma mídia voltada ao entretenimento, fantasia, diversão da leitora, interessada na aquisição de marcas identitárias de seu modo de vida: a maioria dos anúncios da revista está relacionada à moda: 63 anúncios de um total de 86, ou seja, aproximadamente $73 \%$ das publicidades das duas edições: roupas, óculos de grau, óculos de sol, bolsas, sapatos, maquiagem, perfume, joias, relógios, acessórios. 
Na composição verbal e visual dessas publicidades, portanto, estão marca e imagem, seguidos da indicação do site para o comércio eletrônico dos produtos da marca (Santos; Assis; Pascoal; Gonzales, 2019). Essa revista de moda, em seu conteúdo editorial e suas mensagens mercadológicas, converge conteúdo e funções: as imagens de ambas são fotografias de moda ou ensaios fotográficos de alta qualidade - com a assinatura do fotógrafo, informações sobre a modelo, informações sobre a fotografia e/ou ensaio-; e o destaque é para a marca e não o produto apresentado no anúncio. Plataformas digitais da marca e redes sociais não são frequentes nas publicidades da Vogue Brasil, o que indica a relação do público com essa mídia impressa em que é possível ver, apreciar, fruir da estetização das imagens e seus significados, emoções, afetos e ilusões, conceitos dessa lifestyle com a qual o público se identifica e se projeta.

\section{Projeção e identificação da leitora nas páginas da revista Vogue Brasil e os olimpianos}

Nas edições de março e abril da Vogue Brasil, a cultura de massa está alicerçada em um sistema de projeções e identificações específicas (Morin, 1997) da sua leitora financeiramente independente, com poder aquisitivo elevado, interessada em consumir produtos de qualidade, que tem o objetivo de viajar e de conhecer vários lugares e que está preocupada com as tendências do mundo da moda. Conteúdo editorial e publicidades hibridizam-se, na divulgação centrada nas grifes internacionais, anunciando as tendências no cenário da moda mundial. A Vogue não se constitui como uma referência de estilo e tendências apenas para as brasileiras, mas aponta para o que está em evidência nas passarelas de todo o mundo. Das mais de cinquenta marcas que estampam as páginas das edições analisadas, muitas delas se destacam entre as mais valiosas do mundo, anunciadas para um público com condições financeiras para consumi-las, o que reforça a percepção de que o consumo é cultural, definidor de subjetividades e se apresenta como um fato cultural.

De acordo com pesquisa realizada pelos grupos WPP e pela Kantariii, que listou as marcas mais valiosas do mundo em 2018, das dez primeiras no ranking, apenas uma não conta com anúncios nas edições analisadas neste artigo. Por ordem crescente, considerando as organizações que ocupam as primeiras posições, Louis Vuitton, Gucci, Chanel, Rolex, Cartier, Burberry, Prada, Dior e Saint Lauren, estão entre os 86 anúncios que compõem as edições. O conteúdo publicitário apresentado na publicação, bem como as marcas publicizadas, trazem o universo olimpiano com o qual o público desta revista se identifica e se projeta: as celebridades midáticas (Morin, 1997). Assim como na mitologia grega, a partir do século XX, com o advento e a popularização dos principais meios de comunicação de massa, celebridades se efetivaram em papéis de destaque no cenário cultural, o que estabelece uma relação direta com a motivação do consumo e a criação de desejos:

Os novos olimpianos são, simultaneamente, magnetizados no imaginário e no real, simultaneamente, ideais inimitáveis e modelos imitáveis; sua dupla natureza é análoga à dupla natureza teológica do herói-deus da religião cristã: olimpianas e olimpianos são sobre-humanos no papel que eles encarnam, humanos na existência 
privada que eles levam. A imprensa de massa, ao mesmo tempo que investe os olimpianos de um papel mitológico, mergulha em suas vidas privadas a fim de extrair delas a substância humana que permite a identificação (Morin, 1997, p. 106-107).

No caso da Vogue Brasil, o universo olimpiano aparece representado a partir de um duplo estímulo: as marcas anunciantes e as celebridades que estampam estes anúncios. Os olimpianos destacam-se como modelos de conduta, indicando como as pessoas devem viver. Considerando apenas a edição de março para efeito de comparação, e avaliando apenas o cenário brasileiro, personalidades nacionais estrelam alguns anúncios. As atrizes Bruna Marquezine (Dolce \& Gabbana), Marina Ruy Barbosa (Dolce \& Gabbana e Colcci), Fiorella Mattheis (Arezzo), Dani Calabresa (Arezzo), Alinne Moraes (Monte Carlo) e o ator Cauã Reymond (Colcci), em sua maioria, destacam-se como ícones de beleza, juventude e sensualidade como a leitora Vogue gosta de sentir-se: jovem, bonita com as marcas que veste e se apresenta.

A publicidade, apoderando-se das estrelas para fazer delas modelos de beleza (maquilagens de Elizabeth Arden, de Max Factor), confirma explicitamente seu papel exemplar. Pode-se dizer ainda, de modo mais amplo, que os múltiplos modelos de conduta que dizem respeito a gestos, atitudes, modo de andar, beleza se integram num grande modelo global, o de um estilo de vida baseado na sedução, no amor, no bem-estar. Nesse sentido, as estrelas, em suas vidas, de lazer, de jogo, de espetáculo, de amor, de luxo, e na sua busca incessante da felicidade simbolizam os tipos ideais de cultura de massa. Heróis e heróinas da vida privada, os astros e estrelas são a ala ativa da grande corte dos olimpianos, que animam a imagem da verdadeira vida. (Morin, 1997, p. 108).

A composição das publicidades da revista Vogue Brasil simboliza a relação de afetividade da leitora com a revista e as marcas que divulga, num contexto imagético requintado, fotografia ou ensaio fotográfico de uma celebridade, olimpiano, representando tendências, ideais imaginados desse público que valoriza a beleza, sucesso profissional, jovialidade, sensualidade.

\section{Considerações finais}

A linha editorial da Vogue Brasil dita moda não apenas no vestuário, mas apresenta um estilo de vida: como viver, viajar, comer e decorar a casa. Uma publicação referência no país em elegância e sofisticação, principalmente na versão em papel, que possibilita uma estetização no conteúdo que veicula, razão de essa mídia impressa permanecer no mercado editorial, mesmo já estando no meio digital desde 1996. A relação das leitoras com essa revista advém da fruição do esmero das fotografias de modelos, ensaios fotográficos, imagens cinematográficas que encarnam os modelos de cultura de massa.

Mas não só a linha editorial dessa mídia indica tendências: jornalismo e publicidade hibridizam-se de tal forma que a composição das publicidades da revista configura-se de forma glamourosa, espetacularizada, priorizando a imagem e a marca. A estratégia das publicidades do segmento da moda segue a mesma configuração da linha editorial e apodera-se dos olimpianos também em ensaios fotográficos ou fotografias 
conceituais de uma celebridade midiática, associados a uma marca de luxo, projetando modelos e lifestyle com a qual o público se identifica.

Os olimpianos presentes nas mensagens publicitárias representam o imaginário do público que se alimenta do real e vice-versa, em ideais de beleza, sucesso profissional, jovialidade e sensualidade. Esse processo é realizado por meio da ação dos meios de comunicação de massa, em especial, as publicidades que associam o significado das imagens e das marcas a celebridades midiáticas para extravasar a subjetividade das leitoras e estimular o consumo de bens em um universo de luxo.

\section{Referências}

Douglas, m.; Isherwood, B. (2004) O mundo dos bens: para uma antropologia do consumo. Tradução Plínio Dentzien. Rio de Janeiro: Editora UFRJ.

Galindo, Daniel dos S. (2012) Comunicação Mercadológica uma revisão conceitual. In: GALINDO, Daniel dos S. (Org.). Comunicação Institucional e Mercadológica: Expansões conceitual e Imbricações temáticas. São Bernardo do Campo: Editora metodista.

Leitão, D. K.; Pinheiro-Machado, R. (2010) Tratar as coisas como fatos sociais: metamorfoses nos estudos sobre cultura material. In: Mediações. Londrina, v. 15, n.2, p. 231-247, Jul/Dez.

Morin, E. (1997) Cultura de massas no século XX: neurose. Tradução de Maura Ribeiro Sardinha. $9^{a}$ ed. Rio de Janeiro: Forense Universitária.

Morris, P. K.; Waldman, J. A. (2011). Culture and Metaphors in Advertising: France, Germany, Italy, the Netherlands, and the United States. In: International Journal of Communication, vol. 5, p.942-968, 2011. Disponível em: <https://ijoc.org/index.php/ijoc/article/view/853/573>. Acesso em: 25 jul. 2019.

Retondar, A. M. (2008) A (re)construção do indivíduo: a sociedade de consumo como "contexto social" de produção de subjetividades. In: Sociedade e Estado, Brasília, v. 23 , n. 1, p. 137-160, jan./abr.

Rocha, E. (2005) Culpa e prazer: imagens do consumo na cultura de massa. In: Comunicação, mídia e consumo. São Paulo, vol. 2, n. 3, p. 123-138, mar.

Santos, Tarcyane Cajueiro. (2011) A sociedade de consumo, os media e a comunicação nas obras iniciais de Jean Baudrillard. In: Revista Galáxia. São Paulo, n. 21, p. 125-136, jun.

Santos, A. C. H. ; ASSIS, B. L. ; PASCOAL, J. S.; GONZALES, L. S. (2019) A composição das publicidades da revista Veja na cibercultura e era da convergência cultural. In: Congresso de Ciências da Comunicação na Região Sudeste, XXIV, 3 a 5 de junho de 2019, Vitória (ES). Anais...São Paulo: Intercom. Disponível em: 
$<\quad$ http://portalintercom.org.br/anais/sudeste2019/resumos/R68-0167-1.pdf>. Acesso em: 25 jul. 2019.

\section{Notas}

i Disponível em: https://vogue.globo.com/

ii Mídia Kit 2018 Vogue Brasil. Disponível em: <http://estaticos.edglobo.globo.com/vogue/MediaKit/VG_midiakit_2018_atualizado.pdf〉. Acesso em: 01 abr. 2019.

iii A lista completa foi publicada pelo site Exame e está disponível no link https://exame.abril.com.br/marketing/as-10-marcas-de-luxo-mais-valiosas-do-mundo-em-2018/ 